\title{
A Study on Triassic Shale Gas Reservoir Characteristics from Ordos Basin
}

\author{
Xiangrong Luo, Shuzhong Wang ${ }^{\mathrm{a}}$, Zefeng Jing, Guixi Xu \\ Key Laboratory of Thermo-Fluid Science and Engineering, Ministry of Education, School of Energy \\ and Power Engineering, Xi'an Jiaotong University, Xi'an, Shaanxi, 710049, China \\ aszwang@aliyun.com
}

\begin{abstract}
Keywords: continental shale, mineral composition, pore structure, specific surface areas
Abstract. The Triassic continental shale from Ordos basin was selected as the research object, through the analysis of X-ray diffraction (XRD), field emission scanning electron microscopy (SEM) and nitrogen adsorption experiment, the mineral composition and pore structure characteristics of Triassic continental shale from Ordos basin have been investigated in detail. X-ray diffraction analysis result shows that the mineral composition is mostly composed of clay minerals and silica minerals, with minor contributions made by carbonate minerals. The clay mineral content ranges from $40.5 \%$ to $66.0 \%$ with an average of $55.8 \%$, and the silicoide mineral content accounts for $22.4 \%$ to $58.3 \%$. Compared with marine shale gas reservoir, Triassic continental shales from Ordos basin are characterised by high clay mineral content. The shale samples show high specific surface areas of $1.1 \sim 22.9 \mathrm{~m}^{2} \cdot \mathrm{g}^{-1}$.
\end{abstract}

\section{Introduction}

Shale gas is stored differently depending on three types of geological environment: free gas in pores and/or fractures, gas sorbed onto kerogen and clay minerals and, to a lesser extent, gas dissolved in residual bitumen. Successful exploration and production of shale gas in USA has greatly encouraged investigations into the composition (both organic and inorganic) and the gas potential of shales from North America and Europe in the past ten years[1]. In the past few years, Chinese geologists have shown increasing interest in the composition and gas potential of shales. Marine shale gas has recently gained significant success in USA, and it has triggered a worldwide fever for shale hydrocarbon resources. In China, marine shale gas has been widely studied[2]. In contrast, there has been little work done and less attention paid to continental shale hydrocarbons. In this study, we selected continental shales from the Triassic Yanchang formation in southern Ordos basin to investigate their essential character containing mineral composition, organic matter content, microstructure, etc. This study has a certain guiding significance for the future exploration and development of shale gas in Ordos basin.

\section{Samples and material}

The shale samples originated from the depth of about 2105 2193 $\mathrm{m}$ in southern Ordos basin were prepared for the experimental work. The samples investigated in this work are Mesozoic Triassic shale. The samples were crushed to pass through a $0.5 \mathrm{~mm}$ sieve, deriving a particle size of $500 \mu \mathrm{m}$ for adsorption tests, while the fraction $<500 \mu \mathrm{m}$ was used for total organic carbon (TOC) measurements and X-ray diffraction (XRD) analysis. The surface of samples for scanning electron microscopy (SEM) needs doing gold-plated treatment.

\section{Results and discussions}

\section{Mineral composition}

The mineralogical composition for tested samples is presented in Fig 1. As is seen from Fig 1, Minerals of shale samples mainly include the clay minerals and silica minerals (quartz and feldspars). All shale samples studied are quite rich in clay minerals. The clay mineral content ranges from $40.5 \%$ to $66.0 \%$ with an average of $55.8 \%$, and the silicoide content accounts for $22.4 \%$ to $58.3 \%$ with an 
average of $36.4 \%$. Carbonate mineral content ranges from $1.2 \%$ to $22.1 \%$ with an average of $8.5 \%$. Clay minerals are essentially composed of illite-montmorillonite mixed-layer, illite and chlorite. The illite-montmorillonite mixed-layer is the most abundant clay mineral and in the clay minerals its content account for $39.3 \% \sim 64.6 \%$. The illite content account for $18.2 \%$ 29.3\%. A small amount of chlorite also present in a number of samples. However, illite is generally the most abundant clay mineral in other gas shales[3].

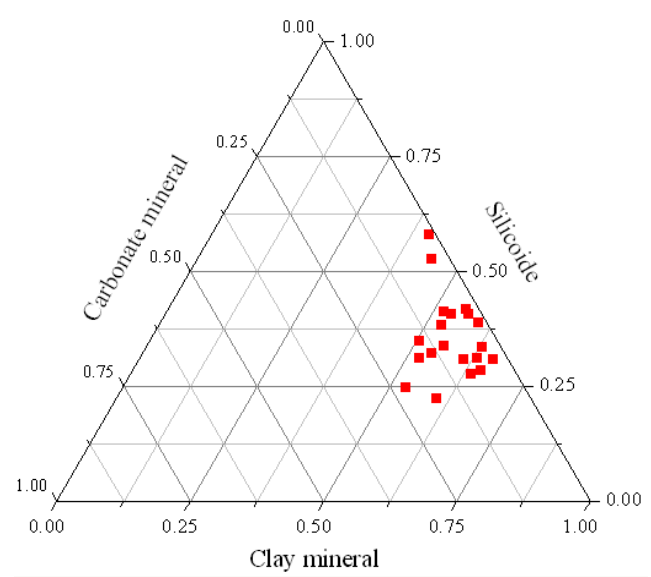

Fig.1. Mineral composition of shale samples studied

\section{SEM results}

In this study, scanning electron microscopy (SEM) test of shale samples were performed. The test results are shown in Fig 2 and Fig 3. Fig 2 shows microscopic structure of main minerals of shale samples. According to the XRD analysis above, clay minerals of Triassic shale mainly contain illite-montmorillonite mixed-layer and illite. The shale sample scanning electron microscopy (SEM) results also confirm that the illite-montmorillonite mixed-layer are well developed in Triassic shale, and fibrous-honeycomb illite-montmorillonite mixed-layer can be observed (Fig 2c). Meanwhile the distribution of fibrous illite between pore throat is also observed (Fig 2a), and the regular quartz particles can be seen clearly (Fig 2b). The long strip shaped feldspar is also observed (Fig 2d). Many types of pores are present in the shale samples, including intergranular pore, intragranular dissolved pore and intercrystalline pore. The intergranular pore of clay mineral is one of the most important pore types in this study (Fig 3a, 3c, 3d). In addition, the intragranular dissolved pores are also developed (Fig 3b, 3d). Through the microstructure observation it is found that the pore shape of shale samples is very irregular and the slit type pore is mainly developed in the study area (Fig 3a, 3b, 3c, 3d).

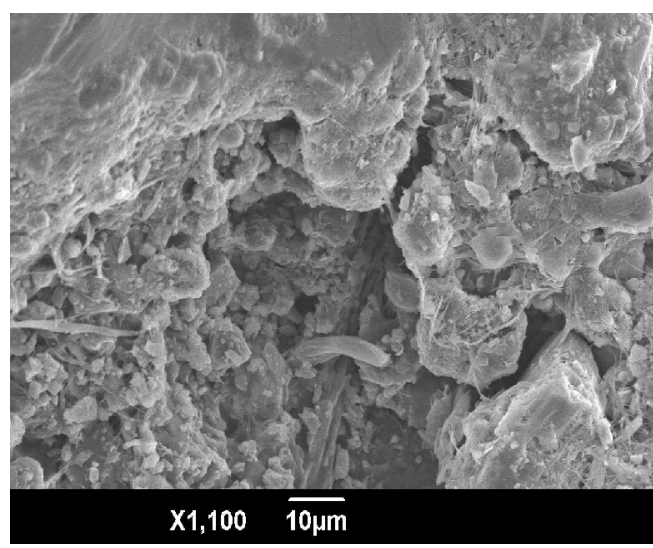

(a) illite

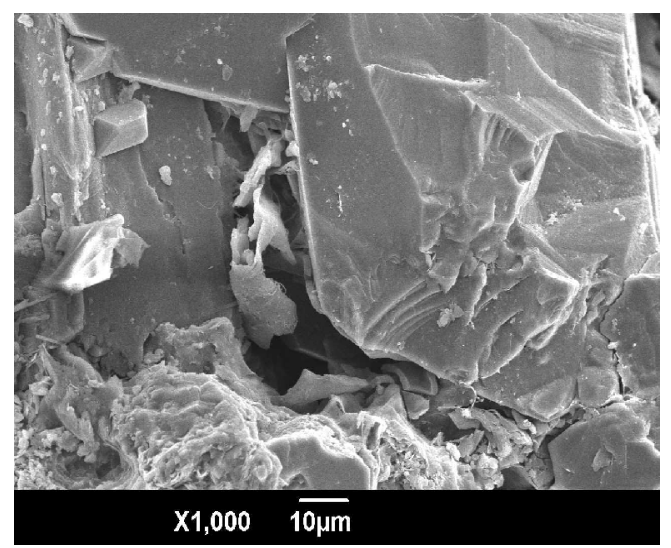

(b) quartz 


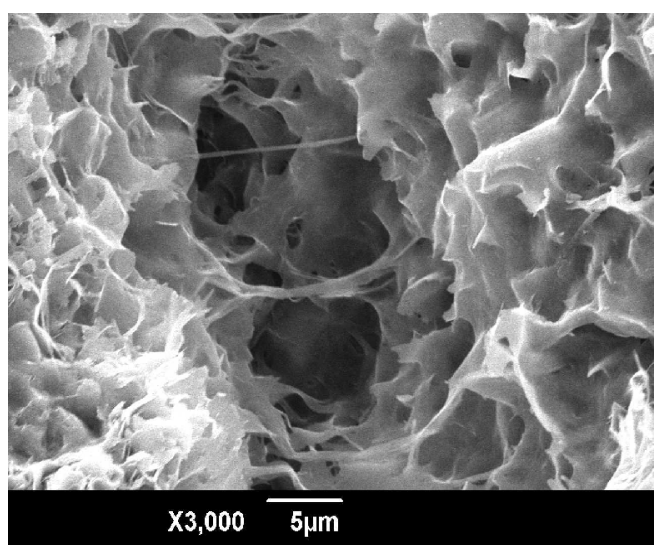

(c) illite-montmorillonite mixed-layer

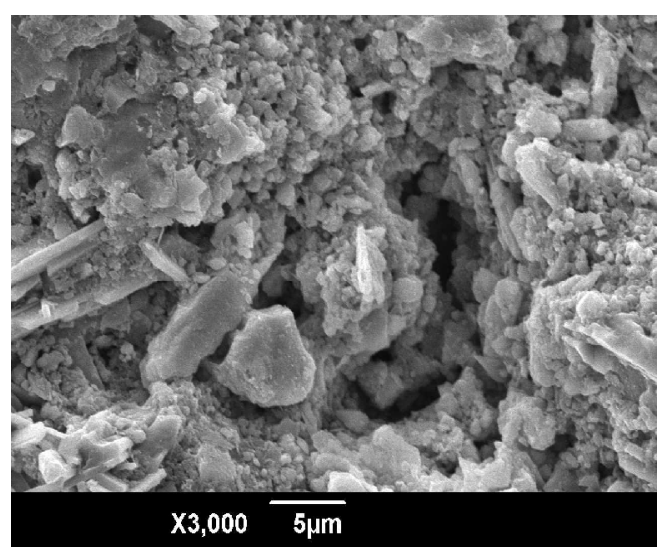

(d) feldspar

Fig.2. Shale mineral morphological characteristics in the study area

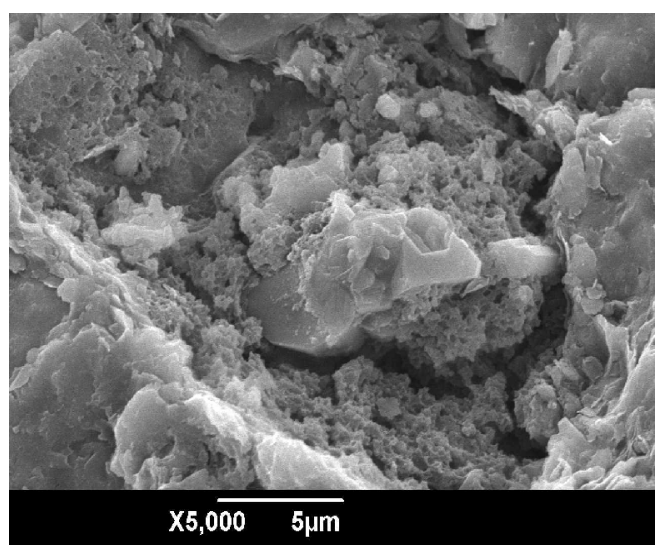

(a) intergranular pore

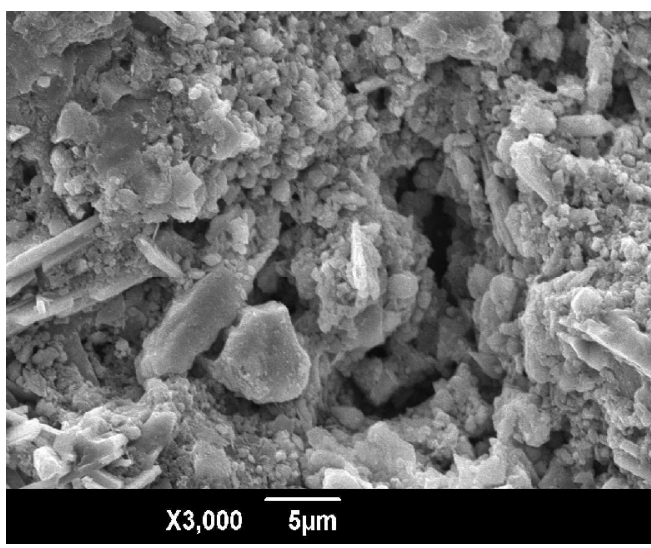

(c) intergranular pore and intercrystalline pore

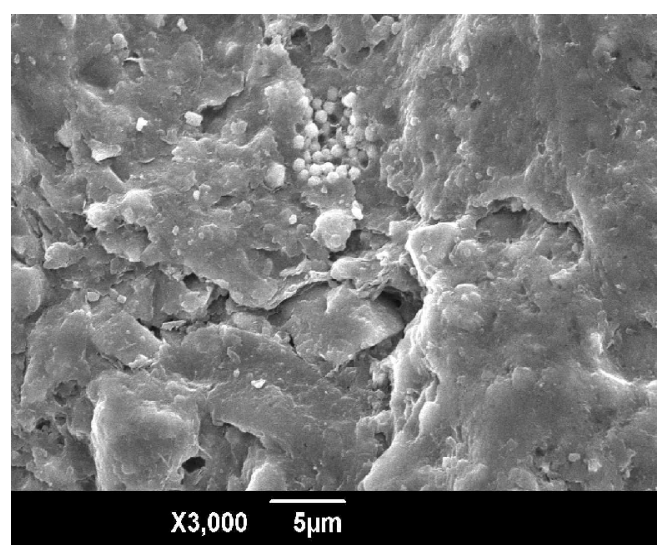

(b) intragranular dissolved pore and intercrystalline pore

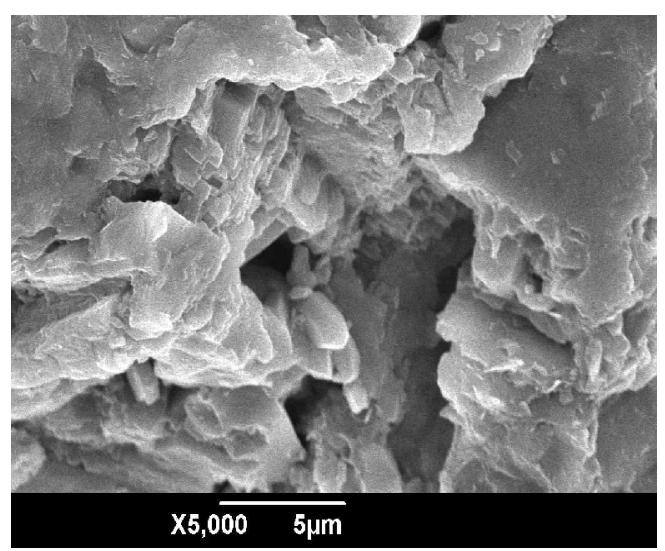

(d) intergranular pore and intragranular dissolved pore

Fig.3. Shale pore type and pore configuration in the study area

\section{Nitrogen adsorption results}

The shale samples show high specific surface areas of $1.1 \sim 22.9 \mathrm{~m}^{2} \cdot \mathrm{g}^{-1}$. The average specific surface area is $7.3 \mathrm{~m}^{2} \cdot \mathrm{g}^{-1}$. Comparatively speaking, the specific surface areas of the shale samples are much more than that of the sandstone and coal samples. As shale has larger specific surface area, its gas adsorption capacity is strong and its development cycle is very long. The pore size distributions of the samples are shown in Fig 4. The shale samples have a broad pore size distribution with a large amount of micropores $(<2 \mathrm{~nm})$, mesopores $(2 \sim 50 \mathrm{~nm})$ and macropores $(>50 \mathrm{~nm})$ according to the pore size 
classification of the International Union of Pure and Applied Chemistry (IUPAC). Fig 4a indicates that for mesopores and macropores of shale samples the average pore width is 2 160 nm, mainly centering on $10 \sim 70 \mathrm{~nm}$. Fig $4 \mathrm{~b}$ shows that the micropores of the shale samples have a centralized distribution of $0.4 \sim 1 \mathrm{~nm}$.

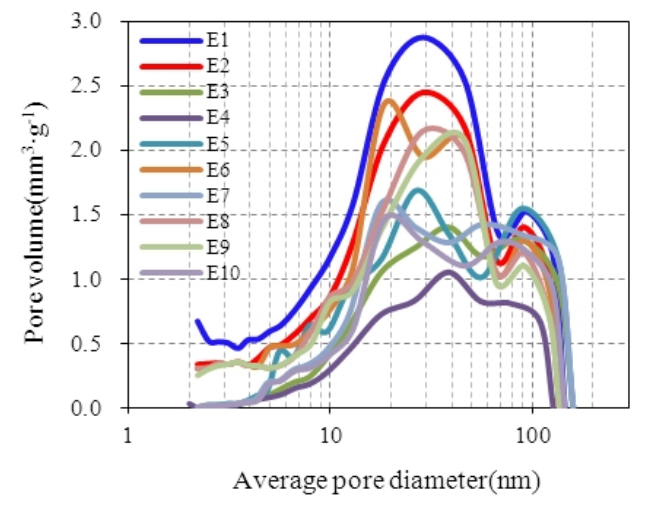

(a) Mesopores (2-50 nm) and macropores (>50 nm)

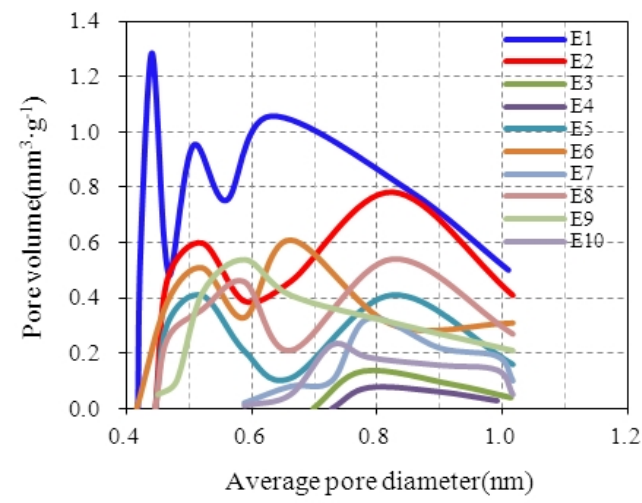

(b) micropores $(<2 \mathrm{~nm})$

Fig.4. Measured pore size distribution for samples

\section{Conclusion}

The minerals of Triassic continental shale in southern Ordos Basin include illite-montmorillonite mixed-layer, illite, quartz, etc. The clay mineral is the most important mineral constituent, accounting for $40.5 \%$ to $66.0 \%$. The shale samples show high specific surface areas. For the shale samples, the mesopores account for a higher proportion, mainly centering on $10 \sim 70 \mathrm{~nm}$. The pore types of shale samples in the study area are complicated, including intergranular pore, intragranular dissolved pore and intercrystalline pore, thereinto, intergranular pore is foremost. SEM and nitrogen adsorption test all indicate that from the point of pore configuration the slit pores are well developed in the shale samples studied. The Triassic continental shale in southern Ordos basin has its own characteristics, which are significantly different from those of marine shales documented in the USA, it is necessary to explore new development technology combined with reservoir reality.

\section{Acknowledgements}

The research was supported by Project 2015KTCL01-08 of Shaanxi province science and technology program. The authors would like to acknowledge the state key laboratory of multiphase flow in power engineering in $\mathrm{Xi}^{\prime}$ an Jiaotong University for laboratory equipment support to our research.

\section{References}

[1] M. Gasparik, P. Bertier, Y. Gensterblum, et al. Geological controls on the methane storage capacity in organic-rich shales[J]. Int. J. Coal Geol, 2014, 123: 34-51.

[2] T.T. Cao, Z.G. Song, S.B. Wang, et al. Characterizing the pore structure in the Silurian and Permian shales of the Sichuan Basin, China[J]. Mar. Petrol. Geol, 2015, 61: 140-150.

[3] G.R.L. Chalmers, R.M. Bustin. Lower Cretaceous gas shales in northeastern British Columbia, part I: geological controls on methane sorption capacity[J]. Bull. Can. Pet. Geol, 2008, 56: 1-21. 